\title{
Reduced Free-Radical-Trapping Capacity and Altered Plasma Antioxidant Status in Cystic Fibrosis
}

\author{
S. C. LANGLEY, R. K. BROWN, AND F. J. KELLY \\ Department of Cardiovascular Research, The Rayne Institute, St. Thomas' Hospital, London, SE1 7EH, \\ Uniled Kingdom
}

\begin{abstract}
Plasma antioxidant status and total radicaltrapping antioxidant potential (TRAP) of children $(n=24)$ with cystic fibrosis (CF) were compared with those of children $(n=21)$ without the disease. Children with CF were found to have elevated plasma concentrations of ascorbic acid $(94.6 \pm 58.2 \mu \mathrm{mol} / \mathrm{L})$, with respect to normal children $(65.6 \pm 18.8 \mu \mathrm{mol} / \mathrm{L})$. Plasma uric acid $(330.8 \pm$ 84 versus $198.0 \pm 31 \mu \mathrm{mol} / \mathrm{L} p<0.01)$ and sulfhydryl group $(518 \pm 43$ versus $363 \pm 31 \mu \mathrm{mol} / \mathrm{L} p<0.01)$ concentrations were also elevated in CF. Vitamin $\mathrm{E}$ levels $(16.9 \pm 1.8$ versus $18.4 \pm 1.3 \mu \mathrm{mol} / \mathrm{L}$ ) were at the low end of the normal range. Despite an overall increased antioxidant array, CF patients had a reduced TRAP capacity (488 \pm 34 versus $580 \pm 79 \mu \mathrm{mol} / \mathrm{L}, p<0.05)$. TRAP measurements in $\mathrm{CF}$ patients showed a strong negative correlation $(r=0.80, p<0.001)$ with high ascorbic acid concentration, suggesting a prooxidant effect of ascorbic acid. Oral administration of ascorbic acid to adults was found to diminish TRAP activity. Concentrations of ascorbic acid similar to those seen in CF patients were attained in ascorbatesupplemented individuals, with substantial decreases in TRAP capacity. These studies suggest that high plasma ascorbic acid levels in children with CF may have a prooxidant effect. This appears to reduce the extracellular antioxidant defense of these children and may increase susceptibility to oxidative stress. (Pediatr Res 33: 247-250, 1993)
\end{abstract}

\section{Abbreviations}

ABAP, 2-azobis (2-amidinopropane) hydrochloride $\mathrm{CF}$, cystic fibrosis

OH, hydroxyl radical

TRAP, total radical-trapping antioxidant potential

TRAP ${ }_{\text {calc }}$, theoretically determined total radical-trapping antioxidant potential

TRAP $_{\text {meas, }}$ experimentally determined total radical-trapping antioxidant potential

TRAP $_{\text {diff, }}$ difference between TRAP $P_{\text {meas }}$ and TRAP $P_{\text {calc }}$

$\mathbf{T}_{\text {Trolox }}$, length of induction period during which the Trolox reduces the rate of oxygen loss

$T_{\text {plasma }}$, length of induction period during which endogenous antioxidants reduce the rate of oxygen loss

Free radical species have been implicated in the etiology of a

Received Junc 19, 1991; accepted October 8, 1992.

Correspondence: Dr F. J. Kelly, Cardiovascular Research. The Rayne Institute, St Thomas's Hospital, Lambeth Palace Road. London, SE1 7EH. UK.

Supported by funds from the Cystic Fibrosis Trust and the Nuffield Foundation. S.L. is supported by a grant from the Agricultural and Food Research Council, and R.K.B. is a Cystic Fibrosis Trust postgraduate student. wide variety of human disease states ranging from atherosclerosis (1), cancer (2), and arthritis (3) to bronchopulmonary dysplasia of the premature infant (4). The ability of an individual to withstand the damaging effects of free radicals depends upon the antioxidant capacity of the body. Antioxidants fall primarily into three classes: enzymic antioxidants (superoxide dismutase, catalase, glutathione peroxidase) (5); nonenzymic antioxidants, such as vitamins $\mathrm{C}$ and $\mathrm{E}$, uric acid, glutathione, albumin, and albumin-bound bilirubin $(6-11)$; and metal-binding compounds such as ferritin and ceruloplasmin.

Patients with CF have an impaired ability to absorb fats from the gastrointestinal tract, as a consequence of their reduced secretion of pancreatic enzymes (12). A repercussion of this is a deficiency of the principal fat-soluble antioxidant vitamin $\mathrm{E}$ (13, 14). In addition, deficiencies of other circulating antioxidants, such as ferritin and serum albumin, have been reported in CF patients $(15,16)$. Children with $C F$ are also deficient in selenium $(14,17)$, which is essential for the activity of the antioxidant enzyme glutathione peroxidase (18). Glutathione peroxidase activities in CF patients have, however, been reported to be normal (19). It has been suggested that combined selenium and vitamin E deficiencies in $\mathrm{CF}$ patients attaining adulthood may contribute to the development of cancers (14). Activity of superoxide dismutase and catalase in erythrocytes of $\mathrm{CF}$ patients has been shown to be elevated, indicating that these individuals may be undergoing an intracellular oxidative stress (20). This hypothesis is supported by studies of lipid peroxidation markers in $\mathrm{CF}$ patients (21-23). Evidence for an extracellular oxidant/antioxidant imbalance has been observed in the lungs of young adults with CF $(24,25)$.

The transient existence of free-radical species makes it impractical to measure them in vivo, so most studies focus on their damaging effects on cellular components, notably the peroxidation of polyunsaturated fatty acids (5). In 1985, Wayner et al. (26) developed the total TRAP assay. This assay requires only a small sample of plasma and measures the subject's capacity to buffer a sample of linoleic acid against peroxidation, using a heat-labile initiator ABAP as a source of free radicals. The peroxidation of linoleic acid is followed as a decrease in the free oxygen content of the sample in a Clark cell.

In the present study, the TRAP assay was used to investigate the proposal that CF patients may have a decreased capacity to withstand free-radical stress as a consequence of their reported antioxidant deficiencies.

\section{SUBJECTS AND METHODS}

Chemicals. All chemicals used were obtained from Sigma Chemical Co. (Poole, UK) or BDH Pharmaceuticals Ltd. (Poole, $\mathrm{UK}$ ), with the exception of ABAP (Polysciences, Warrington, UK) and Trolox C (Aldrich, Gillingham, UK).

Subjects. Venous blood samples were drawn from either 
healthy children or patients with CF. CF patients were attending the $\mathrm{CF}$ clinic at Southampton General Hospital for a regular checkup and were not presenting with specific problems. The mean age of the CF group was 8 y 4 mo $(n=24$, age range 2$18 \mathrm{y}$ ). The control group used in the study was a group of healthy children attending Southampton General Hospital or outpatient clinics for minor surgical procedures (Table 1) with a mean age of $7 \mathrm{y}$ and $11 \mathrm{mo}(n=21$, age range $2-17 \mathrm{y})$. Ethical permission for this study was obtained from the Joint Ethical Subcommittee, Southampton and South West Hampshire Health Authority.

Sample handling. Heparinized blood samples from $\mathrm{CF}$ patients and controls were centrifuged at $2000 \mathrm{rpm}, 4^{\circ} \mathrm{C}$, for $10 \mathrm{~min}$. Plasma was stored at $-20^{\circ} \mathrm{C}$ for up to $6 \mathrm{wk}$ before assays. TRAP activity and antioxidant concentrations were stable over this period.

Determination of TRAP activity. TRAP was determined using a modification of the method of Wayner et al. (26). One hundred $\mu \mathrm{L}$ of plasma were mixed with $10 \mu \mathrm{L}$ of linoleic acid in a glass vial by vortexing for approximately $30 \mathrm{~s}$. Fifty $\mu \mathrm{L}$ of the plasmalinoleic acid mixture were added to a Perspex oxygen electrode cell (Rank Brothers, Bottisham, UK), containing $3 \mathrm{~mL}$ of PBS, $\mathrm{pH} 7.5$, and $30 \mu \mathrm{L}$ of $0.4 \mathrm{M} \mathrm{ABAP}$, at $37^{\circ} \mathrm{C}$. Light was excluded from the cell to prevent photodecomposition of the ABAP. Oxygen loss from the cell, representing oxygen uptake during the peroxidation of the linoleic acid, was followed until the rate of loss was maximal. At this point, $25 \mu \mathrm{L}$ of $0.4 \mathrm{mM}$ Trolox $\mathrm{C}$ were added.

The experimentally measured value of TRAP (TRAP $\left.{ }_{\text {meas }}\right)$ was calculated from the equation:

$$
\begin{aligned}
& \mathrm{TRAP}_{\text {meas }}=\mathrm{Ri} \times \mathrm{T}_{\text {plasma }} \\
& \mathrm{Ri}=2(\text { Trolox } \mathrm{C}) / \mathrm{T}_{\text {Trolox }}
\end{aligned}
$$

where $\mathrm{Ri}$ is the rate of peroxyl radical generation from the decomposition of ABAP at $37^{\circ} \mathrm{C}$ and $\mathrm{T}_{\text {plasma }}$ and $\mathrm{T}_{\text {Trolox }}$ are the respective lengths of the induction periods during which the plasma antioxidants or Trolox $\mathrm{C}$ buffers against the maximal rate of oxygen loss (Fig. 1).

Determination of vitamin $E$. One hundred $\mu \mathrm{L}$ of plasma were extracted with $100 \mu \mathrm{L}$ of anhydrous HPLC grade ethanol and $400 \mu \mathrm{L}$ of HPLC grade hexane. $\alpha$-Tocopherol acetate was added as an internal standard. The hexane layer was removed and evaporated to dryness under a stream of nitrogen. The extract was redissolved in $400 \mu \mathrm{L}$ of HPLC grade methanol, and $100 \mu \mathrm{L}$ aliquots were analyzed by HPLC. A $7 \times 100 \mathrm{~mm}, 5-\mu \mathrm{m} \mathrm{C18}$ column (Jones Chromatography, Hengoed, UK) was eluted with methanol:water $(39: 1 \mathrm{vol} / \mathrm{vol})$, at a flow rate of $0.8 \mathrm{~mL} / \mathrm{min}$. Detection was by UV absorbance at $292 \mathrm{~nm}(27)$.

Determination of vitamin $C$ and uric acid. The HPLC determination of uric acid and ascorbate in plasma was based upon the method of Iriyama et al. (28). One hundred $\mu \mathrm{L}$ of plasma were extracted with $400 \mu \mathrm{L} 2 \%$ metaphosphoric acid and 100 $\mu \mathrm{L}$ HPLC grade heptane. Samples were vortex-mixed for $40 \mathrm{~s}$ and then centrifuged at $13000 \times g$ for $5 \mathrm{~min}$. Twenty- $\mu \mathrm{L}$ aliquots were injected for HPLC analysis. A $10 \times 300 \mathrm{~mm}, 5-\mu \mathrm{m} \mathrm{C} 18$ column (Jones Chromatography) was eluted with a $0.2 \mathrm{M}$

Table 1. Attendance of control children at Southampton General Hospital

\begin{tabular}{lc}
\hline \multicolumn{1}{c}{ Procedure } & No. of patients \\
\hline Nonsurgical outpatients & 8 \\
Orthopedics & 3 \\
Osteotomy & 2 \\
Anal biopsy & 2 \\
Removal of soft tissue & 1 \\
Inguinal hernia & 1 \\
Removal of ingrowing toenail & 1 \\
Excision of ganglion & 1 \\
Atherogram & 1 \\
Unspecified & 1 \\
\hline
\end{tabular}

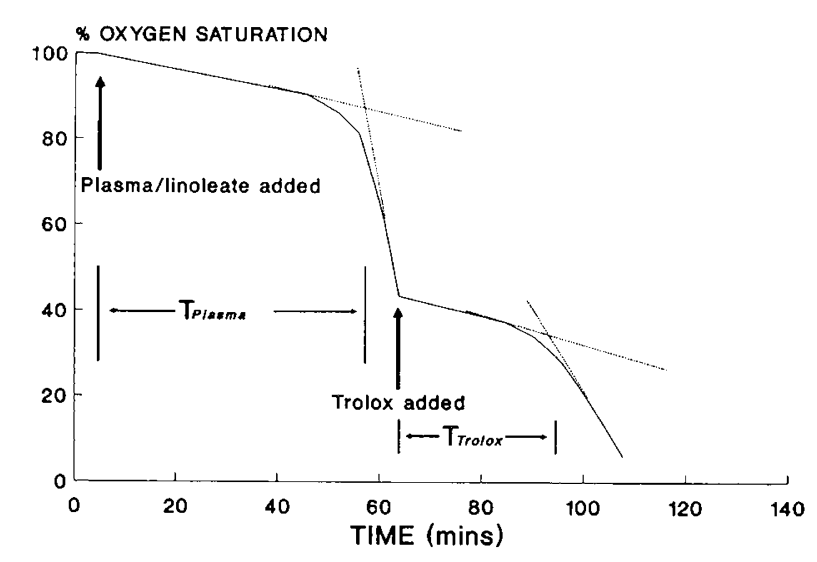

Fig. 1. Schematic representation of TRAP assay $T_{\text {plasma }}$ is taken as the length of time between the addition of the sample to the electrode and the intersection of the slopes of the induction phase and the maximal period of oxygen uptake by the substrate. Trolox $C$ is added to standardize the assay. $T_{\text {Trolox }}$ is taken as the length of time between the addition of Trolox $\mathrm{C}$ and the intersection of the slopes of the Trolox induction phase and the maximal rate of oxygen uptake by the substrate after consumption of the Trolox C.

$\mathrm{K}_{2} \mathrm{HPO}_{4}-\mathrm{H}_{3} \mathrm{PO}_{4}$ buffer, pH 1.5 , containing $0.25 \mathrm{mM}$ octane sulfonic acid, at a flow rate of $1.8 \mathrm{~mL} / \mathrm{min}$. An EG \& G electrochemical detector (Jones Chromatography) was used to detect ascorbate and uric acid, with $\mathrm{E}=810 \mathrm{mV}$, time constant $=5 \mathrm{~s}$, cathodic output, and a sensitivity of $2 \mu \mathrm{A}$.

Determination of total plasma sulfhydryls. Plasma sulfhydryls were assayed by the method of Ellman (29). Twenty-five $\mu \mathrm{L}$ of plasma were added to $975 \mu \mathrm{L}$ of $0.2 \mathrm{M} \mathrm{Na}_{2} \mathrm{PO}_{4}, 2 \mathrm{mM}$ EDTA, pH 9.0, and $20 \mu \mathrm{L}$ of 5,5'-dithio-bis(2-nitrobenzoic) acid (10 $\mathrm{mM}$ in $0.05 \mathrm{M}$ phosphate buffer, $\mathrm{pH} 7.0$ ). Absorbance at 412 $\mathrm{nm}$ was determined against an appropriate blank.

Calculation of theoretical TRAP values. TRAP ${ }_{\text {calc }}$ were calculated from the concentrations of individual antioxidant components of plasma, using stoichiometric values corresponding to the number of peroxyl radicals trapped by each antioxidant molecule $(30,31)$. In the current study, the following equation was used (30):

$$
\begin{aligned}
\operatorname{TRAP}_{\text {calc }}=1.3(\text { urate })+ & x(\text { ascorbate }) \\
& +2(\text { vitamin } E)+0.2(\text { sulfhydryl })
\end{aligned}
$$

The stoichiometric factor for the interaction of ascorbate with free radicals has been shown to vary with the concentration of ascorbate (32-34). Accordingly, the value of $x$ was taken from a sliding scale, in which $\mathrm{x}=2$ at an ascorbate concentration of 1 $\mu \mathrm{mol} / \mathrm{L}$ and $\mathrm{x}=0.3$ at $100 \mu \mathrm{mol} / \mathrm{L}$ (32).

In vivo ascorbate loading experiment. Ten normal, healthy adult volunteers provided a sample of $5-10 \mathrm{~mL}$ of venous blood $5 \mathrm{~min}$ before drinking a $10-\mathrm{mL}$ solution containing $1.5 \mathrm{~g}$ of ascorbic acid or sucrose (control). Three h later, a second blood sample was taken. TRAP activity and plasma ascorbate status were determined in both baseline and postloading samples.

Statistical analysis. Data are presented as median values with ranges. Statistical analysis was performed using the Mann-Whitney $U$ test for nonparametric data. Calculation of correlation coefficients were made using a linear regression analysis program.

\section{RESULTS}

Table 2 shows the plasma concentrations of the four antioxidants studied, in children with CF and in age-matched controls. Ascorbic acid concentrations in the control children ranged from 11.4 to $328.9 \mu \mathrm{mol} / \mathrm{L}$, with 16 of the 21 individuals within the reported normal range of 11 to $100 \mu \mathrm{mol} / \mathrm{L} \mathrm{(35).} \mathrm{Plasma} \mathrm{ascor-}$ bate concentrations were significantly higher $(p<0.05)$ in chil- 
Table 2. Concentrations of antioxidants in plasma*

\begin{tabular}{lcc}
\hline Antioxidant & Control & CF \\
\hline Ascorbic acid & $65.6(11.4-328.9)$ & $94.6(33.7-850.5) \dagger$ \\
Uric acid & $198.0(41.7-502.0)$ & $330.8(59.0-1494.0) \dagger$ \\
Vitamin E & $18.3(14.2-24.5)$ & $16.9(8.6-35.6)$ \\
Sulfhydryls & $363.2(270.6-577.2)$ & $518.4(319.1-1162.0) \dagger$ \\
\hline
\end{tabular}

* Antioxidant concentrations $(\mu \mathrm{mol} / \mathrm{L})$ in plasma from patients with $\mathrm{CF}(n=18-24)$ or age-matched controls $(\mathrm{n}=12-21)$ were compared. Values shown are medians with ranges.

$\dagger$ Statistically different between groups $(p<0.05$ or better). Statistical analysis by Mann-Whitney U test.

dren with CF. They ranged from 33.7 to $850.5 \mu \mathrm{mol} / \mathrm{L}$, with 11 of the 24 patients having plasma ascorbate levels greater than the normal reported range $(>100 \mu \mathrm{mol} / \mathrm{L})$.

Plasma uric acid concentrations (Table 2) were similarly elevated in patients with CF. Nineteen of 21 control children had plasma urate levels within the reported range of 40 to $440 \mu \mathrm{mol} /$ $\mathrm{L}(35)$, the levels of the other two individuals being only marginally higher ( 502 and $547 \mu \mathrm{mol} / \mathrm{L}$ ). CF patients had plasma urate levels ranging from 59 to $1494 \mu \mathrm{mol} / \mathrm{L}$, and although the median concentration was within normal ranges, 10 of 22 individuals had higher than normal urate concentrations.

Vitamin E concentrations (Table 2) were similar in control children and CF patients. In controls, vitamin E levels ranged from 14.16 to $24.46 \mu \mathrm{mol} / \mathrm{L}$, whereas levels of $\mathrm{CF}$ patients were more widely distributed from 8.55 to $35.60 \mu \mathrm{mol} / \mathrm{L}$. A number of the CF patients ( 9 of 18 ) were found to have vitamin $E$ levels at the lower end of the normal range.

Plasma sulfhydryl concentrations were significantly increased in children with CF (Table 2). Control children had sulfhydryl levels ranging from 270.6 to $577.2 \mu \mathrm{mol} / \mathrm{L}$, whereas in $\mathrm{CF}$ patients the range was 319.1 to $1162.0 \mu \mathrm{mol} / \mathrm{L}$.

TRAP $_{\text {meas }}$ activities are shown in Table 3. TRAP $_{\text {meas }}$ in CF patients was significantly lower $(16 \%)$ than in controls. TRAP ${ }_{\text {calc }}$ were, however, greater in CF patients than in controls (not

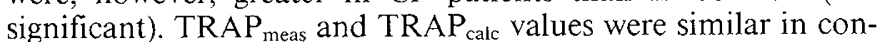

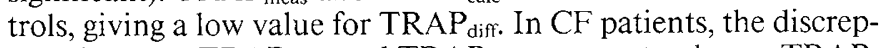
ancy between TRAP ${ }_{\text {mcas }}$ and TRAP calc $_{\text {was }}$ wreater; hence TRAPdiff was significantly higher in this group than in controls. TRAP ${ }_{\text {diff }}$ was found to correlate strongly with plasma ascorbate concentrations among the CF patients $(r=0.801, p<0.00001)$ but not in the age-matched control group $(r=-0.160, \mathrm{NS})$.

To further investigate the influence of ascorbate on TRAP meas, a series of eight healthy adult volunteers were orally administered $1.5 \mathrm{~g}$ of ascorbic acid, $5 \mathrm{~min}$ after a blood sample was taken. Three $h$ later, a second blood sample was taken and the TRAP meas $_{\text {. }}$ and plasma ascorbate levels in the two blood samples were compared (Table 4). Two control adults who were administered

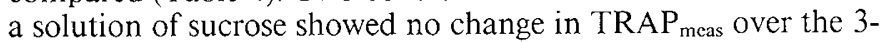
$h$ period. In this period, the mean plasma ascorbate concentration of those individuals receiving ascorbate increased from 42.5 \pm 14.7 (range $25-63$ ) $\mu \mathrm{mol} / \mathrm{L}$ to $108 \pm 87.2$ (range $37-280$ )

Table 3. Experimentally derived plasma TRAP activity and theoretical TRAP parameters*

\begin{tabular}{ccl}
\hline Measurement & \multicolumn{1}{c}{ Control } & \multicolumn{1}{c}{ CF } \\
\hline TRAP $_{\text {mcas }}$ & $580(254-1640)$ & $488(182-692) \dagger$ \\
TRAP $_{\text {caic }}$ & $411(232-829)$ & $623(286-2240)$ \\
TRAP $_{\text {diff }}$ & $-46(-579-382)$ & $480(-330-1796) \dagger$ \\
\hline
\end{tabular}

* TRAP capacity $(\mu \mathrm{mol} / \mathrm{L})$ in plasma from patients with $\mathrm{CF}$ or agematched controls was compared. TRAP ${ }_{\text {meas }}$ indicates experimentally derived TRAP; TRAP ${ }_{\text {calc }}$ indicates theoretical TRAP values determined from the equation shown in Subjects and Methods. TRAP diff is the difference between measured and theoretical TRAP (TRAP calc $_{-}-$TRAPmeas). For TRAP meas $_{\text {control, }} n=20$; for $\mathrm{CF}, n=22$. For TRAP $\mathrm{Tal}_{\text {cal }}$ and TRAP $_{\text {diff }}$ control, $n=10$; for $\mathrm{CF}, n=18$. Values shown are medians with ranges.

$\uparrow$ Statistically different between groups ( $p<0.05$ or better). Statistical analysis by Mann-Whitney U test.
Table 4. Effect of ascorbate on measured TRAP activity in vivo

\begin{tabular}{clccc}
\hline Subject & Treatment & $\begin{array}{c}\text { Initial TRAP } \\
(\mu \mathrm{mol} / \mathrm{L})\end{array}$ & $\begin{array}{c}\text { Final TRAP } \\
(\mu \mathrm{mol} / \mathrm{L})\end{array}$ & $\begin{array}{c}\text { Change } \\
(\%)\end{array}$ \\
\hline 1 & Ascorbate & 564 & 126 & -78 \\
2 & Ascorbate & 760 & 581 & -24 \\
3 & Ascorbate & 246 & 353 & +43 \\
4 & Ascorbate & 867 & 459 & -47 \\
5 & Ascorbate & 1026 & 607 & -41 \\
6 & Ascorbate & 1200 & 1599 & +33 \\
7 & Ascorbate & 1599 & 780 & -51 \\
8 & Ascorbate & 1029 & 564 & -45 \\
9 & Control & 900 & 828 & -8 \\
10 & Control & 499 & 499 & 0 \\
\hline
\end{tabular}

* Normal, healthy adult volunteers were administered $1.5 \mathrm{~g}$ of ascorbic acid orally $5 \mathrm{~min}$ after giving a $5-\mathrm{mL}$ venous blood sample. Three $\mathrm{h}$ later, a second blood sample was taken. TRAP activity was determined in both samples.

$\mu \mathrm{mol} / \mathrm{L}$. Six of the eight individuals showed a $20 \%$ or greater

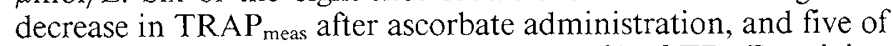
these were observed to lose more than $45 \%$ of TRAP activity. Overall, the decrease in TRAP meas $_{\text {for all eight subjects was not }}$ significant $(991 \pm 409$ to $633 \pm 436 \mu \mathrm{mol} / \mathrm{L})$. The two individuals not showing decreased TRAP meas $_{\text {after ascorbate dosing had }}$ increases of TRAP activity in excess of $30 \%$.

\section{DISCUSSION}

The data obtained in this study indicate that some of children with CF have elevated concentrations of three plasma antioxidants: ascorbic acid, uric acid, and sulfhydryl groups. Plasma vitamin $\mathrm{E}$ concentrations in the majority of $\mathrm{CF}$ patients were similar to those of age-matched controls. This particular finding was not surprising, as vitamin $\mathrm{E}$ status of CF patients attending the outpatients clinic at Southampton has been monitored over the past 5 y and supplements have been recommended where necessary. This approach has led to a normalization of plasma vitamin $\mathrm{E}$ concentrations in $\mathrm{CF}$ patients over this period.

The major surprise of this study was the elevated levels of the other antioxidants assessed. Plasma uric acid concentrations of 59 to $1494 \mu \mathrm{mol} / \mathrm{L}$ were observed; these were significantly higher than urate concentrations in controls. Normal plasma urate levels in children have previously been reported to be in the range of 60 to $440 \mu \mathrm{mol} / \mathrm{L}$ (36), and a similar range is reported for adults (35). The median plasma urate value for CF patients $(330.8$ $\mu \mathrm{mol} / \mathrm{L})$ was slightly above the mean value $(270 \mu \mathrm{mol} / \mathrm{L})$ previously observed in CF patients (37). In the present study, some CF patients had urate levels markedly greater than the highest values reported by Davidson et al. (650-740 $\mu \mathrm{mol} / \mathrm{L})(37)$. Elevated urate levels in urine and plasma have been previously reported in children with $\mathrm{CF}(38,39)$ and have been attributed to the high purine content of the pancreatic enzyme supplements these children receive. In the current study, all the CF patients were receiving supplements of the pancreatic enzyme preparation Creon (Reid-Rowell, Marietta, GA). Increased plasma urate levels have also been indicated in children who are below normal height and weight for their age and who suffer repeated infections (36), as is the case with CF children. 
Mean plasma ascorbate levels in CF patients were $44 \%$ higher than in age-matched controls and were distributed over a range of 33 to $850 \mu \mathrm{mol} / \mathrm{L}$. Eleven of the $24 \mathrm{CF}$ patients had plasma concentrations above the normal reported range, 11 to $100 \mu \mathrm{mol} /$ L (35). This was also true of some (five of 20) of the controls. Two of the control subjects with high ascorbate concentrations were vegetarian. Dietary and vitamin supplement information was not available from control children, but was obtained retrospectively for six CF patients with the highest concentrations of ascorbate (data not shown). None of these patients was taking supplements or had dietary ascorbate intakes sufficient to explain his or her elevated plasma concentrations. Indeed, no clear relationship between ascorbate intake and plasma ascorbate levels was observed in these patients. The explanation for the high ascorbate levels in CF patients is thus obscure but may result from a reduced rate of clearance, an increased release, or slow uptake by the tissues, which are known to have higher ascorbate concentrations than plasma (34).

Despite this increased antioxidant capacity, CF patients were found to have decreased TRAP meas compared with age-matched controls. This finding suggests that CF patients have a reduced capacity to withstand oxidative stress, such as that which they experience during periods of infection when activated phagocytes release free radicals as part of the respiratory burst. Indeed, there is already evidence that CF patients undergo oxidative stress. These include elevated markers of lipid peroxidation, an increase in intracellular antioxidant defenses (20-23), and a 100- to 1000 fold elevation in the number of neutrophils in the airways of the lung (25). This increase in neutrophil numbers in the respiratory tract is likely to subject the airway to an extracellular oxidant stress (25). Depressed extracellular glutathione concentrations in the lung have been linked to a number of pulmonary pathologies, including $\mathrm{CF}$, idiopathic pulmonary fibrosis, smoking-related lung injury, and HIV infection $(24,40,41)$.

In summary, children with CF were found to have increased plasma concentrations of urate, sulfhydryl compounds and ascorbate, with vitamin E levels at the low end of the normal range. In spite of an increased array of extracellular scavenging antioxidants, CF patients were found to have a reduced total peroxyl trapping antioxidant potential. This appeared to be linked to their high ascorbate levels and may be attributable to the prooxidant activity of ascorbate. The study suggests that children with CF may have a reduced ability to withstand oxidative damage.

Acknowledgments. The authors thank Dr. C. Rolles, Dr. S. Peters, Professor J. O. Warner, and Dr. A. Postle. We also thank B. Astin, T. Meakins, and C. Persaud for their excellent technical assistance.

\section{REFERENCES}

1. Harats D, Ben-Naim M, Dabach V, Hollander G, Haviv E, Stein O, Stein Y 1990 Effect of vitamins and vitamin $C$ and $E$ supplementation on susceptibility of lipoproteins to peroxidation induced by smoking. Atherosclerosis $85: 47-54$

2. Cheeseman KH, Collins M, Proudfoot K, Slater TF, Burton GW, Webb AC, Ingold KU 1986 Studies on lipid peroxidation in normal and tumour tissues. Biochem J 235:507-514

3. Flohe L 1988 Superoxide dismutase for therapeutic use: clinical experience, dead ends and hopes. Mol Cell Biochem 84:123-131

4. O'Brodovich HM, Mellins RB 1985 Bronchopulmonary dysplasia. Unresolved neonatal acute lung injury. Am Rev Respir Dis 132:694-709

5. Freeman BA, Crapo JD 1982 Biology of diseases: free radicals and tissue injury, Lab Invest 47:412-426

6. Niki E, Saito T, Kamiya Y 1983 The role of vitamin C as an antioxidant. Chem Lett 5:631-632

7. Frei B, Stocker R, England L, Ames BN 1990 Ascorbate, the most effective antioxidant in human blood plasma. Adv Exp Med Biol 264:155-163

8. Niki E 1987 Antioxidants in relation to lipid peroxidation. Chem Phys Lipids 44:227-253
9. Stocker R, Glazer AN, Ames BN 1987 Antioxidant activity of albumin-bound bilirubin. Proc NatI Acad Sci USA 84:5918-5922

10. Kornbrust DJ, Maus RD 1980 Relative susceptibility of microsomes from lung, heart, liver, kidney, brain and testes to lipid peroxidation: correlation with vitamin $E$ content. Lipids 15:315-322

11. Halliwell B 1988 Albumin: an important extracellular antioxidant? Biochem Pharmacol 37:569-571

12. Kohler JA, Rolles CJ 1986 Therapeutic progress: review XVIII. Cystic fibrosis. J Clin Hosp Pharm 11:21-32

13. Bye AME, Muller DPR, Wilson J, Wright VM, Mearns MB 1985 Symptomatic vitamin $E$ deficiency in cystic fibrosis. Arch Dis Child 60:162-164

14. Stead RJ, Redington AN, Hinks LJ, Clayton BE, Hodson ME, Batten; JC 1985 Selenium deficiency and possible increased risk of carcinoma in adults with cystic fibrosis. Lancet 8460:862-863

15. Ehrhardt P, Miller MG, Littlewood JM 1987 Iron deficiency in cystic fibrosis. Arch Dis Child 62:185-187

16. Ater JL, Herbst JJ, Landaw SA, O'Brien RT 1983 Relative anemia and iron deficiency in cystic fibrosis. Pediatrics 71:810-814

17. Dworkin B, Newman LJ, Berezin S, Rosenthal WS, Schwarz SM, Weiss L 1987 Low blood selenium levels in patients with cystic fibrosis compared to controls and healthy adults. J Parenter Enteral Nutr 11:38-41

18. Lawrence RA, Burk RF 1976 Glutathione peroxidase activity in seleniumdeficient rat liver. Biochem Biophys Res Commun 71:952-958

19. Lloyd-Still JD, Ganther HE 1980 Selenium and glutathione peroxidase levels in cystic fibrosis. Pediatrics 65:1010-1012

20. Matkovics B, Gyurkovits K, Laszlo A, Szabo L 1990 Altered SOD values in erythrocytes from children with Duchenne muscular dystrophy and cystic fibrosis. In: Greenwald RA, Cohen G (eds) Oxy Radicals and Their Scavenger Systems. Elsevier Science Publishing Co., New York, pp 411-415

21. Bilton D, Maddison J, Webb AK, Seabra L, Jones M, Braganza JM 1991 Cystic fibrosis, breath pentane and lipid peroxidation. Lancet 337:1420(abstr)

22. Bilton D, Seabra L, Jones M, Webb AK, Braganza JM 1990 High breath pentane levels in patients with cystic fibrosis. Clin Sci 79:20P(abstr)

23. Salh B, Webb K, Guyan PM, Day JP, Wickens D, Griffin J, Braganza JM, Dormandy TL 1989 Aberrant free radical activity in cystic fibrosis. Clin Chim Acta 181:65-74

24. Roum JH, Buhl R, McElvaney NG, Borok Z, Hubbard RC, Chernick M, Cantin AM, Crystal RG 1990 Cystic fibrosis is characterized by a marked reduction in glutathione levels in pulmonary epithelial lining fluid. Am Rev Respir Dis 141:A87 (abstr)

25. Roum JH, Buhl R, McElvaney NG, Borok Z, Hubbard RC, Chernick M Cantin AM, Crystal RG 1990 In vitro evaluation of the ability of glutathione to suppress the inflammatory cell derived oxidant burden in respiratory epithelial lining fluid of individuals with cystic fibrosis. Clin Res 38:440A (abstr)

26. Wayner DDM, Burton GW, Ingold KU, Locke S 1985 Quantitative measurement of the total peroxyl radical-trapping antioxidant capability of human blood plasma by controlled peroxidation. FEBS 187:33-37

27. Kelly FJ, Rodgers W, Handel J, Smith S, Hall MA 1990 Time course of vitamin $E$ repletion in the premature infant. Br J Nutr 63:631-638

28. Iriyama K, Yushiuram M, Iwamoto T, Ozaki Y 1984 Simultaneous determination of uric and ascorbic acids in human serum by reversed-phase high performance liquid chromatography with electrochemical detection. Anal Biochem 141:238-243

29. Ellman GL 1959 Tissue sulphydryl groups. Arch Biochem Biophys 82:70-77

20. Wayner DDM, Burton GW, Ingold KU, Barclay LRC, Locke SJ 1987 The relative contributions of vitamin $\mathrm{E}$, urate, ascorbate and proteins to the total peroxyl-radical trapping activity of human blood plasma. Biochem Biophys Acta 924:408-419

31. Lindeman JHN, VanZoeren-Grobben D, Schrijver J, Speek AJ, Poorthuis JHM, Berger HM 1989 The total free radical trapping ability of cord blood plasma in preterm and term babies. Pediatr Res 26:20-24

32. Wayner DDM, Burton GW, Ingold KU 1986 The antioxidant efficiency of vitamin $C$ is concentration-dependent. Biochem Biophys Acta 884:119-123

33. Niki E, Saito T, Kawakomi A, Kamiya Y 1984 Inhibition of oxidation of methyl linoleate in solution by vitamin $\mathrm{E}$ and vitamin $\mathrm{C} . \mathrm{J}$ Biol Chem 259:4177-4182

34. Bendich A, Machlin LJ, Scandurra O, Burton GW, Wayner DDM 1986 The antioxidant role of vitamin C. Adv Free Radic Biol Med 2:419-444

35. Thurnham DI 1990 Antioxidants and prooxidants in malnourished populations. Proc Nutr Soc 49:247-259

36. Harkness RA, Nicol AD 1969 Plasma uric acid levels in children. Arch Dis Child 44:773-779

37. Davidson GP, Hassel FM, Crozier D, Corey M, Forstner GG 1978 Iatrogenic hyperuricemia in children with cystic fibrosis. J Pediatr 93:976-979

38. Stapleton FB, Kennedy J, Nouisa-Arvanitakis S, Linshaw MA 1976 Hyperuricosuria due to high-dose pancreatic extract therapy in cystic fibrosis. $\mathrm{N}$ Engl J Med 295:246-248

39. Wiersbitzky S, Ballke E-H, Wolk E, Paul W 1989 Uric acid serum concentration in CF children after pancreatic enzyme supplementation. Padiatr Grenzgeb 28:171-173

40. Crystal RG 1991 Oxidants and respiratory tract epithelial injury: pathogenesis and strategies for therapeutic intervention. Am J Med 91(suppl 3C):39-44

41. Cantin AM, North SL, Fells GA, Hubbard RC, Crystal RG 1987 Oxidantmediated epithelial cell injury in idiopathic pulmonary fibrosis. J Clin Invest 79:1665-1673 